\title{
Effect of Implementing Nursing Guidelines on Occurrence of Deep Venous Thrombosis for Critically III Patients
}

\author{
Naglaa A El-Rashedy*, Nagwa A Reda**, Mogedda M Mehany***
}

\begin{abstract}
Deep venous thrombosis (DVT) is a major health problem that results in significant morbidity and mortality for the critically ill patients in the critical care units. It was documented that DVT occurs in about two million Americans each year, whereas pulmonary embolism (PE) as a complication of DVT causes approximately 50.000 to 60.000 deaths. Moreover, it was revealed by a study done in Assuit University Hospital that out of 220 surgical patients, 12 (5\%) died with pulmonary embolism as a complication of DVT. Other research done at Alexandria University in El-Hadra Hospital on 50 orthopedic patients revealed that seven patients were detected with DVT. The critical care nurses are the key players in the prevention of DVT and its complications. They are in the ideal position to asses' patient risk factors early and ask for DVT prophylaxis. Objective: the current study was carried out to evaluate the effect of implementing nursing guidelines on the occurrence of DVT for critically ill patients. Methods: Four critical care unites were used to collect the data for this study at Assuit University Hospital, sixty critically ill patients were included in this study, they were divided into two groups G1 (control group) and G2 (interventional group) 30 patients each. Two tools were used to collect the data of this study. Tool one: "Patient's assessment for DVT, and Tool two: the "DVT evaluation sheet". Results and conclusion: Findings of the current study revealed low incidence of DVT for the global sample, only two patients experienced DVT in the control group, and none of the interventional group experienced DVT. Moreover, it was observed that the preventive measures of DVT done by the critical care nurses for the control group using non-pharmacological and mechanical methods were not adequately performed. In addition, it was found that all the studied patients of control group did not wear the elastic stocking, while small proportion of this group performed leg exercises, changed their position, did deep breathing, and coughing exercises, and transfer on the chair. It was observed that most of the studied patients experienced low percent of DVT manifestations with no statistically significant difference between the both groups. The present study revealed also that nearly half of the studied patients were in moderate \& high risk grades for DVT in the both groups. Recommendations: based on the current study findings it can be recommended that this research should be repeated on a large sample size and in multi centers for generalization. Moreover, training programs should be established to update critical care nurses' knowledge and skills about DVT preventive measures, and how to use the technical skills to assess the occurrence of DVT using the evidence base nursing and medicine.
\end{abstract}

\section{INTRODUCTION}

Deep venous thrombosis (DVT) is practitioner; it can be a primary reason for particularly important to the critical care admission to the critical care unit or

\footnotetext{
${ }^{*}$ Critical Care Nursing Department, Faculty of Nursing, Assuit University, Egypt.

${ }^{* *}$ Critical Care Nursing Department, Faculty of Nursing, Alexandria University, Egypt.

${ }^{* * *}$ Critical Care Nursing Department, Faculty of Nursing, Assuit University, Egypt.
} 
complication of other critical illness ${ }^{(1)}$. United States ${ }^{(2,5)}$. A study done in Assuit Critically ill patients are at great risk for University Hospital revealed that out of 220 developing DVT due to their premorbid surgical patients, $12(5 \%)$ died with PE as a condition, admitting diagnosis in the critical complication of $\mathrm{DVT}^{(6)}$. Other research was care units such as sepsis and trauma; and done at Alexandria University in El-Hadra exposure to invasive procedure such as Hospital (2004) on 50 orthopedic patients central and peripheral venous revealed that seven patient only were catheterization and certain medications as sedative, narcotic, and analgesic. DVT occurs also in critically ill patients who have immobility for an extended period of time ${ }^{(2)}$. Most of the clinical studies of DVT in the critically ill patients estimated that $90 \%$ of cases of pulmonary embolism (PE) originated in the deep venous system of the lower $\operatorname{limb}(3,4)$.

detected with $\quad \mathrm{DVT}^{(3)}$. Previous research has shown that DVT of the lower limbs is primarily responsible for the vast majority of cases of pulmonary embolus in hospitalized patients $^{(7)}$. Recent studies have shown that despite prophylaxis, DVT occurs in approximately $11 \%$ of intensive care patients. A number of reviews have been undertaken in recent years to examine the

It was documented that DVT and development and prevention of DVT in Pulmonary embolism (PE) constitute a intensive care patients ${ }^{(8)}$.

major health problem that result in Critical care nurses are the key players significant morbidity and mortality for in the prevention of DVT and its critically ill in the critical care units. DVT complications. They are in the ideal position occurs in about two million Americans each to assess patient risk factors early and ask year, where as PE causes, approximately for DVT prophylaxis. Admission 50.000 to 60.000 deaths each year in the assessments are an opportune time to 
evaluate patient risk factors such as in hospitalized patients ${ }^{(12)}$. Even with best immobility, age, previous history of DVT, efforts in the critical care unit, it might never and medical conditions that increase the be able to eliminate all cases of venous risk of developing DVT in hospitalized thromboembolism, but it should be patients. Patient risk assessment should be equipped with nursing expertise and the ongoing throughout hospitalization but latest tools for dealing with this potential especially with condition changes ${ }^{(9,10)}$.

killer. Critical care nurses can help reduce

Once a patient is considered at risk for developing DVT, critical care nurses must advocate for timely prevention mechanisms. This can be done by notifying physicians about the risk factors and asking for orders to initiate prophylaxis early or following an established hospital protocols and guidelines $^{(11)}$. Once prophylaxis orders are obtained, they need to be initiated as soon as acute care. Critical care nurses should be well-acquainted with the two forms of the disease (DVT and its dreaded sequel, pulmonary embolism). Preventing and detecting these two conditions have long been essential components of quality nursing. It was documented that PE is the most common undiagnosed cause of death its incidence and save lives ${ }^{(12)}$. Hence this study was carried out to evaluate the effect of implementing nursing guidelines on the occurrence of DVT in critically ill patients.

\section{MATERIAL AND METHOF}

\section{Material}

\section{Design:}

A quasi experimental research design was adopted to conduct this study.

\section{Setting:}

This study was carried out in 4 intensive care units (ICUs) namely, stroke, general, trauma, and post operative ICUs, at Assuit university Hospitals.

\section{Subject:}

The sample of this study comprised of 
60 adult patients including both sex, their admission, and type of ICU.

age ranged from 20-60 years old, and Part II: "DVT risk factors scale", this part admitted to the previously mentioned was initially developed by Autar (1996)(16), settings. They were selected by then it was modified by Abd Elmanam convenience and randomly assigned to two (2004)(3), and further modification was done equal groups, control (G1) and by the researcher based on the literature interventional group (G2) (30 patients review ${ }^{(17-19)}$ to suit the critically ill patients. It each). included nine items as age of the specific

\section{Exclusion Criteria:} group, weight, mobility level, special risk

Any patients with the following category, site of trauma, surgical conditions were excluded from the study: operations, high risk diseases, family - Coronary artery diseases in acute stage. history of DVT, and type of anesthesia.

- $\quad$ Fluid restriction.

- Exercises contraindication.

Part III: "the special biological factors

\section{Tools:}

and therapeutic modalities in the ICU": This part was developed by the researcher

Two tools were used to collect the data in this study and developed by the researcher based on the related literatures $(10,14,15)$.

based on the literature $\operatorname{review}^{(7,20)}$ it included assessment of the hydration status as (skin turgor, mucous membrane, central venous catheter and intake and out put

Tool one: "Patient's assessment for DVT", this tool was developed to assess the patient's risk factors, it included four parts:

Part I: - "patients profile" to document the part was used to assess the preventive patient's name, age, sex, diagnosis, date of measures that were done by the critical 
care nurses for the control group (nursing procedures that are considered to be effective in prevention of DVT), These measures included:

- Applying elastic stocking \& leg elevation (check list ten Items).

- Changing position in bed (check list nineteen Items).

- Deep breathing and coughing exercise (check list ten Items).

- Range of motion of lower limb (check list twelve Items).

- Transferring patient from bed to chair (check list twenty one Items).

Tool two: "DVT evaluation sheet", this tool was developed by the researcher based on the extensive review of related literatures) ${ }^{(21-22)}$, it was used to assess the occurrence of DVT, and to evaluate the effect of nursing guidelines, it included three parts:

Part I: "DVT manifestations", this part was used to assess DVT manifestations as the presence of six items (calf pain, calf tenderness, calf circumference, skin color and distension of superficial vein, and warm calf).

Part II: "Laboratory tests findings" , this part was used to interpret the data related to the laboratory testes findings to determine coagulation status of the patient, as partial thromboplastin time (PTT), prothrambin time $(\mathrm{PT})$, hemoglobin $(\mathrm{HB})$, platelets and, fibrinogen level.

Part III: "Doppler findings", this part was used to assess the blood supply in the veins in the lower limbs, that indicate the occurrence of DVT.

\section{Method}

- Permission to conduct the study was obtained from the responsible authorities of all the selected ICUs after explanation of the aim of the study.

\section{Development of the tools after reviewing} the related literature was done.

- The tools were reviewed by a jury for face clarity, feasibility, applicability, and the content validity of the tools 
and all the necessary modifications were done. The Jury members were ten experts representing related content area. This included 3 medical staff, 2 from Vascular Department, one professor of anesthesia and intensive care, one Critical Care nursing staff from Assuit University, 4 Nursing Faculty staff from Critical Care Nursing Department, and 2 staffs from Nursing Education Department of the Faculty of Nursing, Alexandria University. Reliability was done on the tools by Cronbach's Alpha ranging from 0.80 to 1.00 .

- Informed consent was obtained from each patient or from the responsible person for the unconscious patients.

A pilot study was conducted on 5 patients who met the predetermined selection criteria to test the applicability of the tools. Appropriate study modifications were done prior to data collection.

\section{Data collection:}

The data were collected from the first day of admission after stabilization of the patient's condition and for ten consecutive days, every day and every shift then the data were recorded in the developed tools.

Data were collected on three phases.

Assessment Phase for the control group:

The patients profile was collected from the patient or from nurses if the patient was comatose, and recorded in part I, tool one.

then assessment of the risk factors of DVT was done by the assessment scale using Part II in tool one as the following:-

For the age: $20<30$ years scored -0 , if $30<40$ years scored -1 , if $40<50$ years scored ---2.

- The weight: was assessed by using Chumlea equation(23) the knee height was measured by centimeter tap and recorded in equation to determine the 
body weight, and then divided the weight $(\mathrm{kg})$ on the height $\left(\mathrm{m}^{2}\right)$ to determine the body mass index.

The body mass index: by using Chumlea equation and classify the weight as the following: if $(20<25) \rightarrow$ ideal weight and scored ---o, $(25<30) \rightarrow$ over weight---1 and $(\geq 30) \rightarrow$ obese ---2 .

- Level of mobility: if the patient was ambulant scored---0, if slightly ambulant---1, if very limited---2 and immobile---3.

Special risk category: if female on contraceptive pills scored--1, if pregnant or in the pureperium period scored ---2, if smoking man---3.

Trauma risk factors: these factors were scored only preoperative, if no trauma scored ---0, head \& neck scored ---1 , chest scored---1, chest \& neck---2, spinal---2, pelvic---3, lower limbs---4. After that surgical operation if none ---0, if pelvic---1, orthopedic---2, spinal---3.

- High risk diseases: if none scored ---
0 , if nephrotic syndrome---1, ulcerative colitis---1, anemia---2, if congestive heart failure---3, myocardial infarction--4, malignancy---5, hyper coagulation diseases---6, varicose vein---7, stroke---7.

Family history of DVT: if negative scored---0, if positive---1.

Anesthesia: if spinal scored---0, if general---1 then the entire patient's data were marked in the scale to collect number.

The total score of the risk factors ranged from $\mathbf{1}$ as minimum to 28 as a maximum. The increased number was considered as high risk for development of DVT.

After that assessment of the hydration status was done by observation of the skin turgor and the mucous membrane, then central venous pressure and intake and output was measured and documented in the patient's chart every day and every shift. 
- Then the special therapeutic Evaluation of clinical outcomes for the Modalities were assessed every day patients in the control group (GI):

and every shift (as mechanical ventilator connection, and the medications that the patients received) and recorded in tool one part II.

Assessment of the nursing performance for DVT preventive measures for the control group using check lists. The actual nursing practices related to DVT preventive measures for the patients were observed by the researcher, using DVT prevention check lists that included the following check lists:

- Applying elastic stocking \& leg elevation (check list ten Items).

- Changing position in bed (check list nineteen Items).

- Deep breathing and coughing exercise (check list ten Items).

- Range of motion of lower limb (check list twelve Items).

- Transferring patient from bed to chair (check list twenty one Items).
Data for this group were collected from 30 patients who met the predetermined criteria in the control group who received the routine unit care, using tool two part I (manifestations of DVT), part II (the laboratory tests) and part III (Doppler ultrasound) findings.

- The patient's legs were assessed for DVT manifestations. The assessment included six items, which were scored as follows, calf pain scored as absent (0) or present 1 , calf tenderness absent (0), present (1), calf edema skin color, and, distension of superficial vein and skin temperature of legs (warm calf). All data were recorded in the tool two parts

I. The total score of manifestations scale $=12$.

Total risk category stratifications = total score of risk factors scale (28) + total score of manifestations DVT (12) $[28+12]=40$. 
- To determine the grade of high risk for DVT if $<9$--- No risk, low risk $\quad(9<14)$, moderate risk $(14<21)$ and high risk $\geq 21-40$.

- After that the laboratory data of the its implementation:

patients (prothrombin, time, hemoglobin, haematocrite, platelets, and fibrinogen level were recorded. These laboratory tests were done routinely, these data were recorded in the first day, fifth day, seventh day, and tenth days to determine coagulation status and compare patient's value with normal value.

- Doppler ultrasound was done to evaluate the blood supply flow in the veins of the lower limbs to detect the presence or absence of DVT. This was done in the first day, third day, fifth day, seventh day, and tenth day.

Implementation phase of the DVT preventive nursing guidelines:

- During this phase, the developed DVT preventive guidelines were implemented for the intervention group which consisted of 30 patients who met the predetermined criteria.

The following steps were followed during

\section{Assessment phase:}

Assessment phase was conducted as previously done with the control group.

Implementation phase for the interventional group (G2):

This phase was begun from first day of admission for ten consecutive days every day and every shift.

During this phase the developed nursing guidelines performed to all the studied patients (intervention group).

- These preventive measures were performed by the researcher with assistance of the physiotherapist and the critical care nurses that involved in providing direct patient's care after training on the guidelines.

Measuring the outcome of using DVT nursing guidelines: 
- To evaluate the effect of the nursing - Fisher exact test was used to identify guidelines on the occurrence of DVT for the relationship between DVT the interventional groups, tool two was manifestations, also the relationship used part I (manifestations of DVT), between the level of risk grade and the part II laboratory tests, and part III special risk factors that may have effect Doppler ultrasound findings. As on the occurrence of DVT.

previously done for the control group.

\section{Evaluation phase:} $<0.05$.

- This phase was done to evaluate the

Cronbach`s Alpha was done to test effect of the nursing guidelines on the reliability of the tools.

occurrence of DVT by comparing the results of outcomes of the both groups by using tool two part I, II, III.

\section{Statistical analysis:}

The collected data were coded, analyzed using Statistical Package for Social Sciences (SPSS/ version 13) software, and tabulated.

- Descriptive statistics as number and percent, mean and standard deviation were used.

- Z-test was used. (This test was used to compare between the both groups in relation to sign and symptoms.

\section{RESULTS}

Findings of this study regarding the effect of implementing nursing guidelines on the occurrence of DVT for critically ill patients presented in four parts:-

Part I: Characteristics of the both groups in relation to their profile and DVT risk factors (figure1, 2, 3, 4, table 1, table 2):

Table (1) illustrates characteristics of the both groups (control group (G1), and interventional group (G2) in relation to their profile and DVT risk factors. The mean age of patients in G1and G2 was found to be 
$45.33 \pm 14$ and $45.67 \pm 13.1$, respectively with no statistical significance difference between them. Concerning the gender of the sample, $50 \%$ of the studied patients in G1 and $67 \%$ in G2 were males. Moreover, it was observed that forty four percent of the studied patients in $\mathrm{G} 1$ and $66 \%$ in $\mathrm{G} 2$ were over weight and obese. As for the mobility status, it was found that about $37 \%$ of the studied patients in G1 and 20\% in G2 were with very limited activity, $53 \%$ in $\mathrm{G} 1$ and $70 \%$ in G2 were immobile. Concerning the type of anesthesia, it was indicated that $40 \%$ of the patients in $\mathrm{G} 1$, and $30 \%$ in $\mathrm{G} 2$ received general anesthesia.

Findings of the current study revealed also that patients were selected equally in the two groups from the four types of ICUs, namely stroke, trauma, general, and postoperative ICU. The most common diagnosis in the stoke ICU was found to be $40 \%$ of the patients in $\mathrm{G} 1$ and $60 \%$ in $\mathrm{G} 2$ had cerebral infarction and cerebral hemorrhage. In trauma ICU $40 \%$ of the studied patients in G1and $50 \%$ in G2 experienced head and pelvic trauma. For the patients in the general ICU $60 \%$ in $\mathrm{G} 1$, and $80 \%$ in G2 suffered for respiratory from diseases. While $60 \%$ of the patients in the both groups in the post operative ICU experienced abdominal surgery, and $40 \%$ of the patients had open heart surgery. Concerning the smoking habit, $50 \%$ of the patients in $\mathrm{G} 1$ and $60 \%$ in G2 were smoker from males and the rest of the sample were females and were not smokers.

Table (2) shows the comparison between the two groups in relation to the special biological factors and therapeutic modalities in the ICU. As for the hydration status, $30 \%$ of the studied patients in $\mathrm{G} 1$ and $40 \%$ in G2 had poor skin turgor and dry mucous membrane. Moreover, about 27\% of the studied patients in G1 and about 13\% in G2 had central venous catheter, and 30\% of the studied patients in G1 and only $17 \%$ in G2 had intake and out put chart with negative balance. Fifty percent of the 
studied patients in G1 and 33\% in G2 were connected with mechanical ventilator. Concerning to the given medications, $70 \%$ of the studied patients in $\mathrm{G} 1$, and $60 \%$ in G2 were not receiving anticoagulant. Moreover, $40 \%$ of the studied patients in G1, and $36 \%$ in $\mathrm{G} 2$ did not receive antipyretic analgesic non-steroidal, and $90 \%$ of the studied patients in $\mathrm{G} 1$, and $87 \%$ in G2 did not receive anti-thrombolytic drugs.

Part II: assessment of the DVT preventive measures done by the critical care nurses for the control group (tables 3):

Table (3) indicates the mean and standard deviation of the DVT preventive measures done by the nurses for the control group. It was observed that no body was found in the control group to wear the elastic stocking. The mean number of the studied patients that changed their position in $\mathrm{G} 1$ was found to be $57.03 \pm 17.4$ The mean number of the studied patients in G1 was $2.22 \pm 10.27$ that performed deep breathing and coughing exercises. While the mean number of the patients that performed range of motion for the lower limbs was found to be $10.00 \pm 30.51$. The mean number of the studied patients was found to be $3 \pm 10.0$ that were transferred to the chair.

Part III: Evaluation of the effect of the guidelines as indicated by DVT manifestations and Doppler findings among the both groups. (Tables 4, 5. 6 and 7)

Table (4) presents the DVT manifestations as compared in the both groups (G1, G2). Finding of the current study indicated that calf pain was experienced in about $43 \%$ of the studied patients in $\mathrm{G} 1$, and about $27 \%$ in G2, with no statistical significant difference between the two groups. It was observed that calf tenderness was experienced by $47 \%$ of the studied patients in $\mathrm{G} 1$, and by $33 \%$ of the patients in G2. Calf edema was found to be about $43 \%$ of the studied patients in $\mathrm{G} 1$, and about $33 \%$ in G2 with no statistical 
significant difference between the two significant difference between the both groups. Skin color changes were observed groups.

in $20 \%$ of the studied patients in G1, and

Table (6) indicates the comparison $7 \%$ in G2. Furthermore, distention of between the two groups in relation to the superficial veins was experienced by $13 \%$ of the studied patients in $\mathrm{G} 1$, and $10 \%$ in G2. The warm calf was found to be $53 \%$ of the studied patients in $\mathrm{G} 1$, and $57 \%$ in $\mathrm{G} 2$ with no statistical significant difference between the two groups.

Table (5) depicts the mean and standard deviation of the laboratory tests for the both groups, the mean of the partial thrombin time was found to be $[15.72 \pm 2.57$ and $15.4 \pm 5.12]$, respectively in the both groups. Concerning the mean of the Hemoglobin was found to be $[9.62 \pm 1.45$ and 10.62 \pm 2.11 ] in $\mathrm{G} 1$ and G2, respectively. Regarding the mean of the Hematocrit was found to be $[29.9 \pm 4.35$ and $31.70 \pm 4.16]$ in G1 and G2, respectively. While the mean of the platelets was found to be [272000.4 \pm 98.9 and $237000.6 \pm 77.96]$ in $\mathrm{G} 1$ significant difference between of them. and G2, respectively, with no statistical 


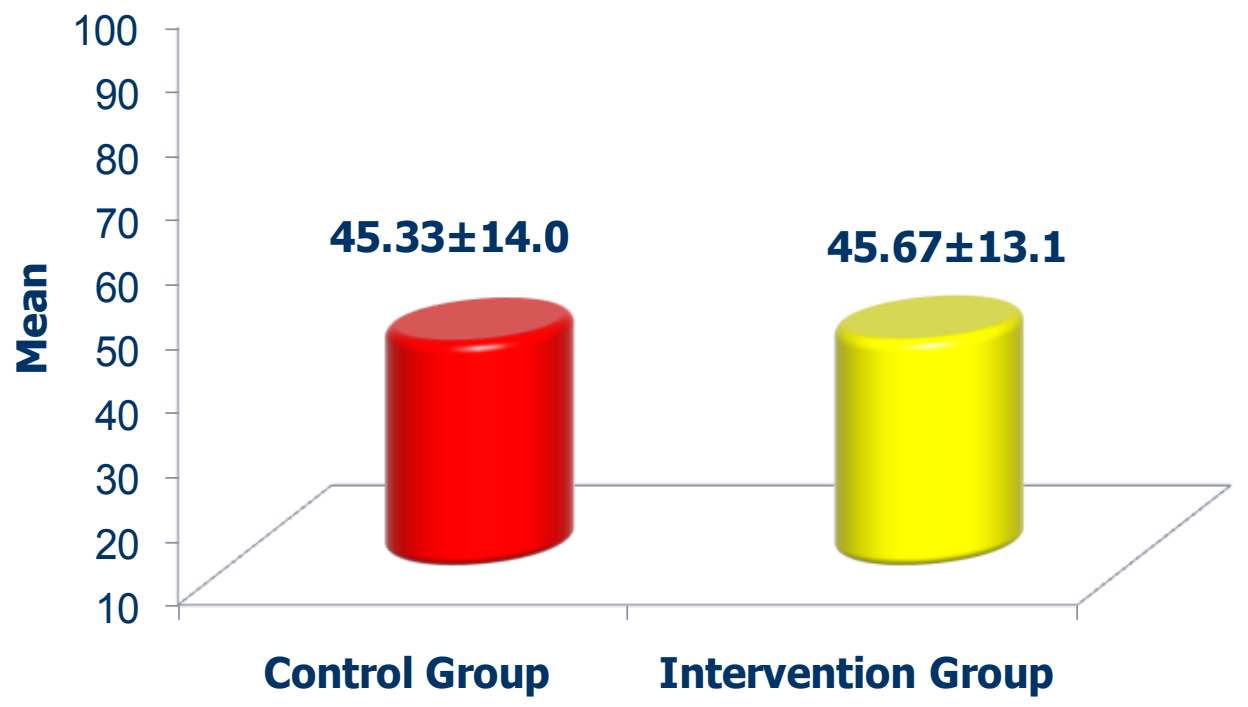

FIGURE (1) THE MEAN PERCENT OF AGE IN THE BOTH GROUPS
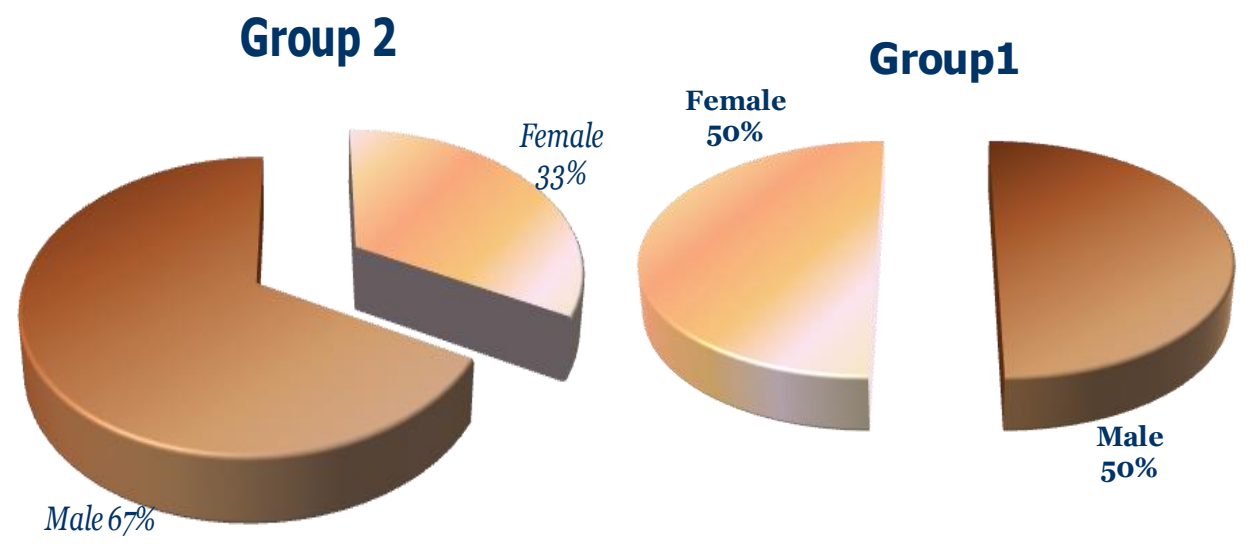

FIGURE (2) PERCENT DISTREBUTION OF THE BOTH GROUPS IN RELATION TO SEX 


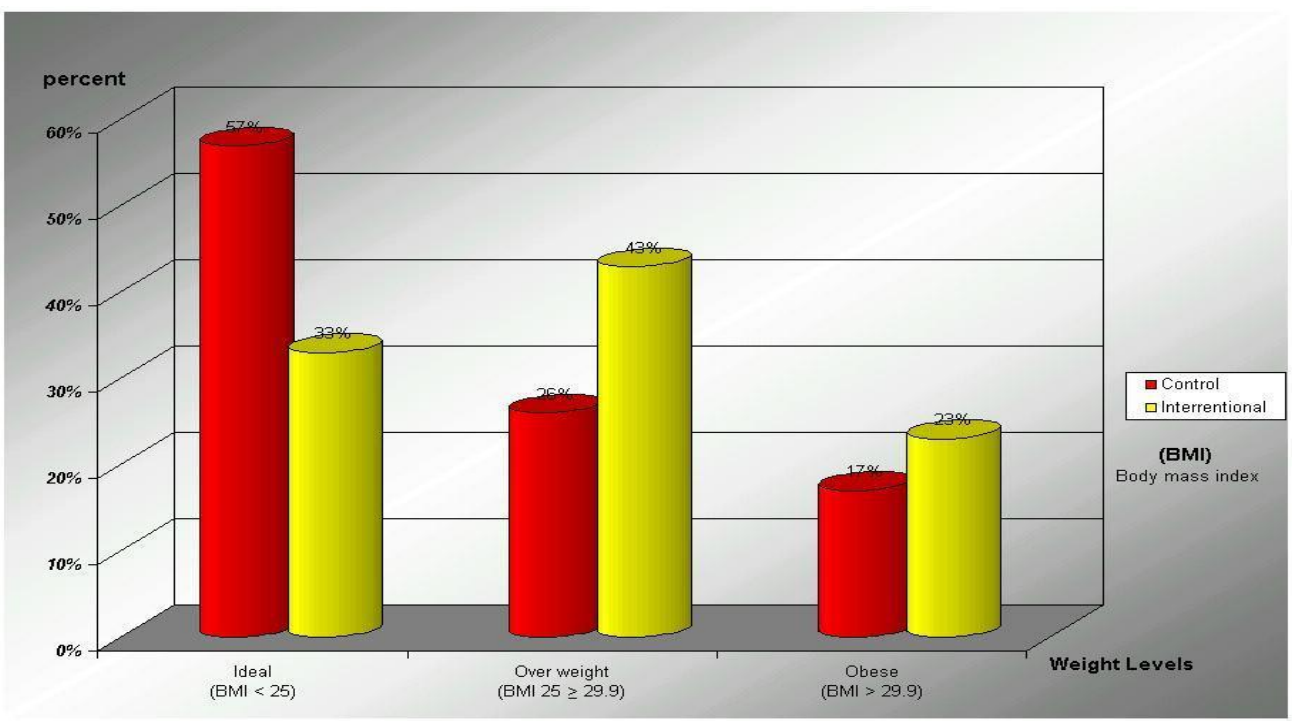

FIGURE (3) PERCENT DISTRIBUTION OF THE STUDY SAMPLE BY WEIGHT IN EACH GROUP.

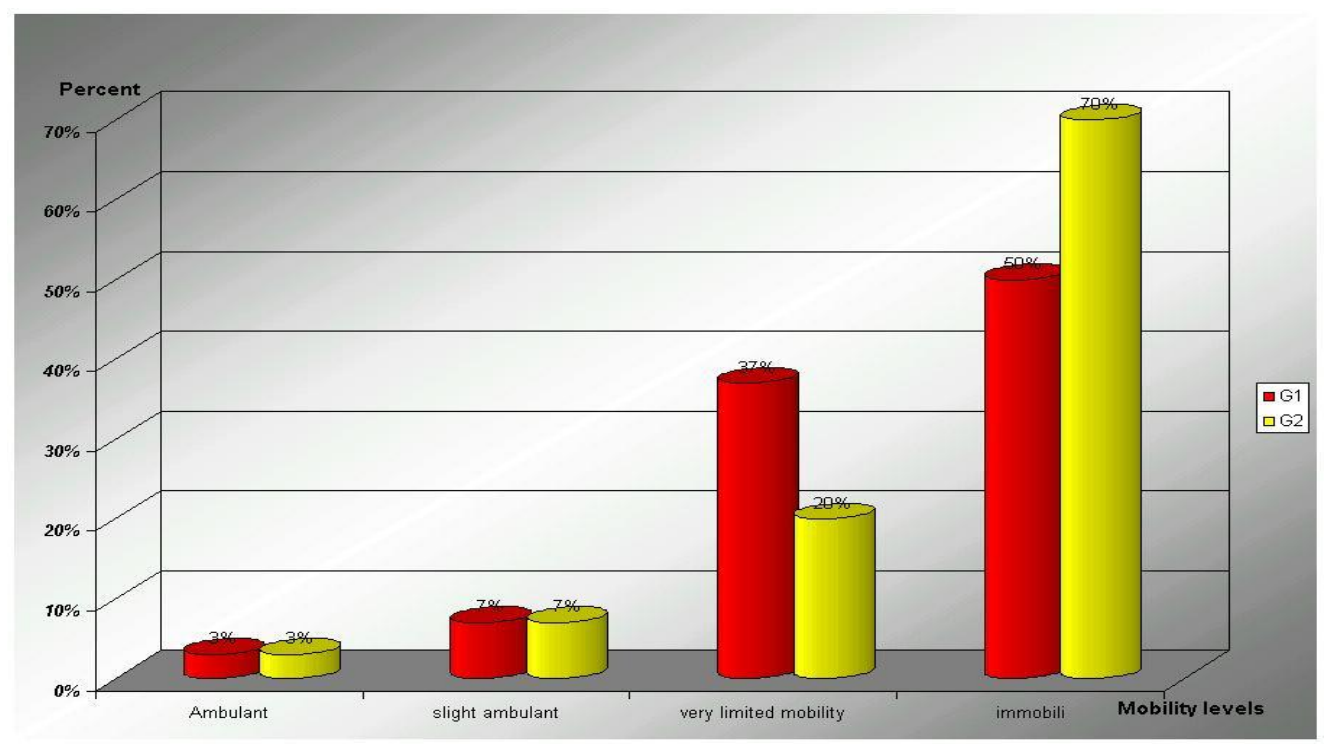

FIGURE (4) PERCENT DISTRIBUTION OF THE STUDY SAMPLE BY MOBILITY LEVELS IN EACH GOUP. 
Part I: Characteristics of the both groups in relation to their profile and DVT risk factors.

Table (1): Characteristics of the both groups in relation to their profile and DVT risk factors.

\begin{tabular}{|c|c|c|c|c|c|}
\hline \multirow[t]{2}{*}{ Variables } & \multicolumn{2}{|c|}{$\begin{array}{c}\text { G1 } \\
\text { No= }=30\end{array}$} & \multicolumn{2}{|c|}{$\begin{array}{c}\text { G2 } \\
\mathrm{No}=\mathbf{3 0}\end{array}$} & \multirow[t]{2}{*}{$\begin{array}{c}\text { Significance } \\
\text { Tests }\end{array}$} \\
\hline & No. & $\%$ & No. & $\%$ & \\
\hline $\begin{array}{l}\text { - Type of (ICU) } \\
\text { - Trauma } \\
\text { - Stroke } \\
\text { - General } \\
\text { - Post operative }\end{array}$ & $\begin{array}{l}10 \\
10 \\
5 \\
5\end{array}$ & $\begin{array}{l}33.3 \\
33.3 \\
16.7 \\
16.7\end{array}$ & $\begin{array}{l}10 \\
10 \\
5 \\
5\end{array}$ & $\begin{array}{l}33.3 \\
33.3 \\
16.7 \\
16.7\end{array}$ & $\begin{array}{l}\chi^{2}=0 \\
P=1\end{array}$ \\
\hline Total & 30 & 100 & 30 & 100 & \\
\hline $\begin{array}{l}\text {-Diagnosis Stroke ICU } \\
\text { - Cerebral infarction } \\
\text { - Cerebral hemorrhage } \\
\text { - Encephalitis }\end{array}$ & $\begin{array}{l}4 \\
5 \\
1\end{array}$ & $\begin{array}{l}40 \\
50 \\
10\end{array}$ & $\begin{array}{l}6 \\
2 \\
2\end{array}$ & $\begin{array}{l}60 \\
20 \\
20\end{array}$ & $\begin{array}{c}Z=.4, p=.34 \\
Z=2.2, p=0.01\end{array}$ \\
\hline Total & 10 & 33.3 & 10 & 33.3 & \\
\hline $\begin{array}{l}\text { - Diagnosis Trauma(ICU) } \\
\text { - Head and pelvic } \\
\text { - Chest }\end{array}$ & $\begin{array}{l}4 \\
6\end{array}$ & $\begin{array}{l}40 \\
60\end{array}$ & $\begin{array}{l}5 \\
5\end{array}$ & $\begin{array}{l}50 \\
50\end{array}$ & $\begin{array}{c}\mathrm{Z}=439, \mathrm{p}=.34 \\
\mathrm{Z}=4.61 \\
\mathrm{p}=0.03\end{array}$ \\
\hline Total & 10 & 33.3 & 10 & 33.3 & \\
\hline $\begin{array}{l}\text { - Diagnosis General( ICU) } \\
\text { - Respiratory diseases } \\
\text { - Drug toxicity } \\
\text { - Hepatic encephalopathy }\end{array}$ & $\begin{array}{l}3 \\
1 \\
1\end{array}$ & $\begin{array}{l}60 \\
20 \\
20\end{array}$ & $\begin{array}{l}4 \\
-- \\
1\end{array}$ & $\begin{array}{l}80 \\
-- \\
20\end{array}$ & $\begin{array}{c}P .41, Z=.23 \\
Z=.01, p=0.496\end{array}$ \\
\hline Total & 5 & 33.3 & 5 & 33.3 & \\
\hline $\begin{array}{l}\text { - Diagnosis Post operative ICU } \\
\text { - Open heart surgery } \\
\text { - Abdominal surgery }\end{array}$ & $\begin{array}{l}2 \\
3\end{array}$ & $\begin{array}{l}40 \\
60\end{array}$ & $\begin{array}{l}2 \\
3\end{array}$ & $\begin{array}{l}40 \\
60\end{array}$ & $\begin{array}{l}Z=.0, p=0.5 \\
Z=.0, p=0.5\end{array}$ \\
\hline Total & 5 & 33.3 & 5 & 33.3 & \\
\hline $\begin{array}{l}\text { - Smoking } \\
\text { - Male } \\
\text { - Yes } \\
\text { - No }\end{array}$ & $\begin{array}{l}15 \\
---\end{array}$ & $\begin{array}{l}50 \\
---\end{array}$ & $\begin{array}{l}20 \\
---\end{array}$ & $\begin{array}{l}60 \\
---\end{array}$ & $\begin{array}{l}\chi^{2}=7.00 \\
P=.402\end{array}$ \\
\hline
\end{tabular}

$\mathbf{P}=0.05$ 
Table (2): Comparison between the two groups in relation to the special biological factors and therapeutic modalities of the studied patients in the ICU.

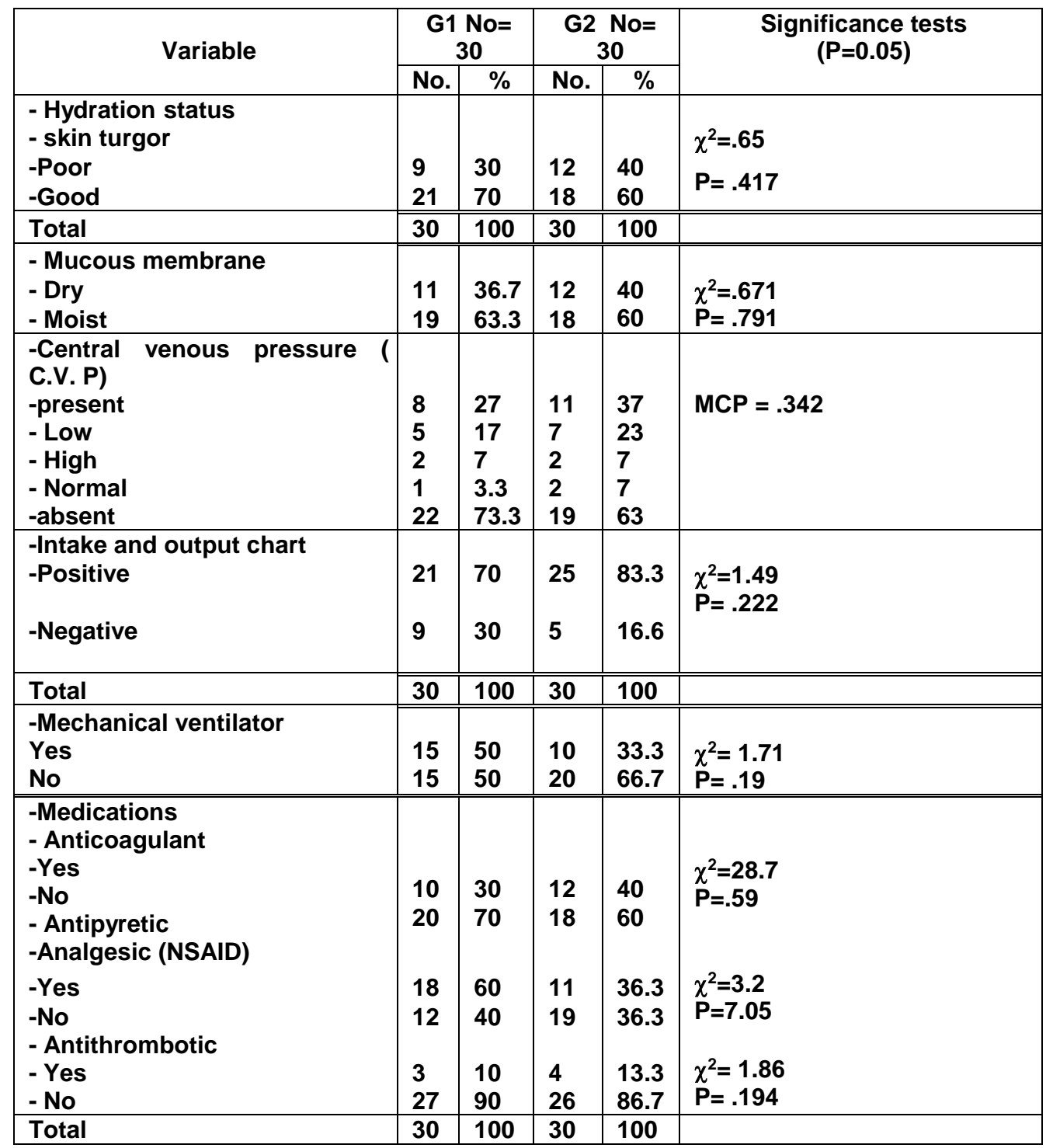

Part II: assessment of the DVT preventive measures done by the critical care nurses for the control group. 
Table (3): Mean percent of patients in the control group in relation to the DVT preventive measures that were performed for them

\begin{tabular}{|l|c|}
\multicolumn{1}{|c}{ Preventive measures. } & :ontrol group (no.= 30) \\
\cline { 2 - 2 } & Mean (SD) \\
\hline - Elastic stocking & ---- \\
\hline - Positioning & $57.03 \pm 17.4$ \\
\hline - Deep Breathing \& cough exercise & $2.22 \pm 10.27$ \\
\hline - Rang of motion & $10.00 \pm 30.51$ \\
\hline - Transferring on the chair & $3.00 \pm 10.0$ \\
\hline
\end{tabular}

Part III: Evaluation of the effect of the guidelines as indicated by DVT manifestations and Doppler findings among the both groups. (Tables 4, 5.6 and 7).

Table (4): DVT manifestations as compared for the both groups.

\begin{tabular}{|c|c|c|c|c|c|}
\hline \multirow[t]{2}{*}{ Manifestations } & \multicolumn{2}{|c|}{$\begin{array}{c}\text { Control G1 } \\
\text { No }=30\end{array}$} & \multicolumn{2}{|c|}{$\begin{array}{c}\text { Interventional G2 } \\
\text { No }=30\end{array}$} & \multirow{2}{*}{$\begin{array}{c}\text { Significance tests } \\
\text { Fisher exact test } \\
\mathbf{P}\end{array}$} \\
\hline & No. & $\%$ & No. & $\%$ & \\
\hline $\begin{array}{ll}- & \text { Calf pain } \\
- & \text { present } \\
- & \text { absent }\end{array}$ & $\begin{array}{l}13 \\
17\end{array}$ & $\begin{array}{l}43.3 \\
56.7\end{array}$ & $\begin{array}{c}8 \\
22\end{array}$ & $\begin{array}{l}26.7 \\
73.3\end{array}$ & $2.86 ¥$ \\
\hline Total & 30 & 100 & 30 & 100 & \\
\hline $\begin{array}{l}\text {-Calf tenderness } \\
\text {-Present } \\
\text { - Absent }\end{array}$ & $\begin{array}{l}14 \\
16\end{array}$ & $\begin{array}{l}46.7 \\
53.3\end{array}$ & $\begin{array}{l}10 \\
20\end{array}$ & $\begin{array}{l}33.3 \\
66.7\end{array}$ & $.492 ¥$ \\
\hline Total & 30 & 100 & 30 & 100 & \\
\hline $\begin{array}{l}\text { - Calf edema } \\
\text { - Present } \\
\text { - Absent }\end{array}$ & $\begin{array}{l}13 \\
17\end{array}$ & $\begin{array}{l}43.3 \\
56.7\end{array}$ & $\begin{array}{l}10 \\
20\end{array}$ & $\begin{array}{l}33.3 \\
66.7\end{array}$ & $.593 ¥$ \\
\hline Total & 30 & 100 & 30 & 100 & \\
\hline $\begin{array}{l}\text { - Skin color } \\
\text { - Present } \\
\text { - absent }\end{array}$ & $\begin{array}{c}6 \\
24 \\
\end{array}$ & $\begin{array}{l}20 \\
80\end{array}$ & $\begin{array}{c}4 \\
28\end{array}$ & $\begin{array}{c}6.7 \\
93.3\end{array}$ & $1.000 ¥$ \\
\hline Total & 30 & 100 & 30 & 100 & \\
\hline $\begin{array}{l}\text { - Distension of superficial vein } \\
\text { - Present } \\
\text { - absent }\end{array}$ & $\begin{array}{c}4 \\
26\end{array}$ & $\begin{array}{l}13.3 \\
86.7\end{array}$ & $\begin{array}{c}3 \\
27\end{array}$ & $\begin{array}{l}10 \\
90\end{array}$ & $1.000 ¥$ \\
\hline Total & 30 & 100 & 30 & 100 & \\
\hline $\begin{array}{l}\text { - Warm calf } \\
\text { - Present } \\
\text { - absent }\end{array}$ & $\begin{array}{l}16 \\
14\end{array}$ & $\begin{array}{l}53.3 \\
46.7\end{array}$ & $\begin{array}{l}17 \\
13\end{array}$ & $\begin{array}{l}56.7 \\
43.3\end{array}$ & $.112 ¥$ \\
\hline Total & 30 & 100 & 30 & 100 & \\
\hline
\end{tabular}

$¥=$ Fisher exact test. 
Table (5): Mean and standard deviation of the laboratory tests for the both groups.

\begin{tabular}{|l|c|c|c|c|}
\hline \multirow{2}{*}{ Laboratory tests } & G1 & \multicolumn{2}{|c|}{ G2 } & \multicolumn{2}{|c|}{ Significance tests } \\
& No. = 30 & No.= 30 & & \\
\cline { 2 - 5 } & Mean St.d & Mean St.d & Z & P \\
\hline -Partial thrombin time (seconds) & $15.72 \pm 2.57$ & $15.4 \pm 5.12$ & 1.526 & .127 \\
\hline -Hemoglobin (g \%) & $9.62 \pm 1.45$ & $10.63 \pm 2.11$ & 2.329 & .020 \\
\hline - Hematocrit (\%) & $29.9 \pm 4.35$ & $31.70 \pm 4.16$ & 2.433 & .015 \\
\hline -platelets (thousand/ cmm) & $272.4 \pm 98.9$ & $237.6 \pm 77.96$ & 1.3 & .193 \\
\hline
\end{tabular}
$P=0.05$

Table (6): Comparison between the two groups in relations to the Doppler findings.

\begin{tabular}{|c|c|c|c|c|c|c|c|c|c|}
\hline \multirow{3}{*}{ Days } & \multicolumn{4}{|c|}{ G I } & \multicolumn{4}{|c|}{ G2 } & \multirow[t]{3}{*}{$\chi^{2} \cdot p$} \\
\hline & \multicolumn{2}{|c|}{ Rt. Leg } & \multicolumn{2}{|c|}{ Left leg } & \multicolumn{2}{|c|}{ Right leg } & \multicolumn{2}{|c|}{ Left leg } & \\
\hline & No. & $\%$ & No. & $\%$ & No. & $\%$ & No. & $\%$ & \\
\hline $\begin{array}{l}\text { 1st day } \\
\text { - present } \\
\text { - absence }\end{array}$ & $\overline{30}$ & $\overline{100}$ & $\overline{30}$ & $\overline{100}$ & 30 & 100 & 30 & 100 & $\chi^{2}=2.06$ \\
\hline $\begin{array}{l}\text { 3rd day } \\
\text { - present } \\
\text { - absence }\end{array}$ & $\overline{30}$ & $\overline{100}$ & --- & $\overline{100}$ & --- & $\overline{100}$ & --- & $\overline{100}$ & $\begin{array}{c}P=.15121 \\
N . S\end{array}$ \\
\hline $\begin{array}{l}\text { 5th day } \\
\text { - present } \\
\text { - absence }\end{array}$ & $\overline{30}$ & $\overline{100}$ & $\begin{array}{c}1 \\
29\end{array}$ & $\begin{array}{c}3 \\
97\end{array}$ & $\overline{30}$ & $\overline{100}$ & --- & $\overline{100}$ & \\
\hline $\begin{array}{l}7^{\text {th }} \text { day } \\
\text { - present } \\
\text { - absent }\end{array}$ & 30 & $\overline{100}$ & $\begin{array}{c}1 \\
29\end{array}$ & $\begin{array}{c}3 \\
97 \\
\end{array}$ & 30 & 100 & 30 & $\overline{100}$ & \\
\hline $\begin{array}{l}10^{\text {th }} \text { day } \\
\text { - present } \\
\text { - absence }\end{array}$ & $\overline{30}$ & $\overline{100}$ & $\overline{30}$ & $\overline{100}$ & $\overline{30}$ & $\overline{100}$ & --- & $\overline{100}$ & \\
\hline
\end{tabular}

$\mathbf{P}=0.05$

Table (7): Patients risk category stratification for both groups.

\begin{tabular}{|c|c|c|c|c|c|c|}
\hline \multirow{2}{*}{$\begin{array}{l}\text { Risk category } \\
\text { Stratification }\end{array}$} & \multicolumn{2}{|c|}{ G1 } & \multicolumn{2}{|c|}{ G2 } & \multicolumn{2}{|c|}{ Test of significant } \\
\hline & No. & $\%$ & No. & $\%$ & $\chi^{2}$ & $\mathbf{P}$ \\
\hline - $\quad$ No risk $<9$ & 4 & 13.3 & 6 & 20 & \multirow{4}{*}{.75} & \multirow{4}{*}{.86138} \\
\hline - $\quad$ Low risk $9<14$ & 8 & 26.7 & 11 & 33.3 & & \\
\hline - $\quad$ Moderate risk14<21 & 16 & 53.3 & 11 & 46.67 & & \\
\hline - High risk $\geq 21$ & 2 & 6.7 & 2 & 6.7 & & \\
\hline Total & 30 & 100 & 30 & 100 & & \\
\hline
\end{tabular}




\section{DISCUSSION}

Critically ill patients with a variety of medical and surgical disorders can develop DVT and pulmonary thromboembolism that complicate their underlying conditions. The diagnosis of pulmonary thromboembolism in such critically ill patients is often difficult to make or confirm. The usual method of treatment with anticoagulation is hazardous and may be contraindicated in some of these patients. Therefore, there is increased emphasis on the prevention of deep venous thrombosis and pulmonary thromboembolism in ICU patients given to that they have multiple risk factors for this disease ${ }^{(11,13,14)}$.

\section{Incidence of DVT:}

Findings of the current study revealed low incidence of DVT in the global sample, only two patients experienced DVT in the control group, and none of the interventional group experienced DVT. This result may be attributed to the small sample size, short period of observation and follow up, and the administration of pharmacological medications of anticoagulant that were given as prophylaxis. Abd Elmanam (2004) $)^{(3)}$ indicated that less than one quarter of the studied patients experienced DVT, which is considered to be low percent in relation to the orthopedic patients. Moreover, Gamal Eldeen (1999)(4) reported that none of her studied abdominal surgical patients developed DVT.

\section{DVT risk factors:}

Wendy et al., (2004) ${ }^{(24)}$ reported that the following risk factors as age, sex, weight, mobility status, trauma, surgical operations, anesthesia, previous history of DVT, and many diseases, all should be considered when determining patients risk for development of venous thromboembolism. Although individual risk factors are important in considering the need for DVT prophylaxis, multiple risk factors lead to an ever greater risk, therefore, the critically ill patients should be 
screened for DVT risk upon admission; and

DVT prevention techniques should be initiated based on the risk assessment.

Findings of the current study revealed apparently that with increasing age there was increase in the risk of DVT in the both groups. Abd Elmonam (2004)(3), and Ebell $(2001)^{(25)}$ reported that the patent's age was found to be a significant factor in the development of DVT in the studied patients. Moreover, Autar (1996) $)^{(16)}$ proved that there was a linear relationship between advanced age and the incidence of DVT. It was documented that the incidence of DVT increases linearly with increasing age, three factors have been proposed to explain this increase. First: as the increased vein age, they lose their elasticity, and the resulting dilatation and tortuosity contributes to an increase in the stasis of blood. Second: the decrease in muscle mass of the venous pump effectiveness add additional venous stasis. Third: there is an increased incidence with associated conditions and diseases, as malignancy, heart disease which predisposes older patients to thromboembolic complications ${ }^{(22)}$.

Gender was documented also to be another factor for DVT development. The gender in the current study sample was found to be equal in $\mathrm{G} 1$, while more than half of the studied patients in G2 were males. Abd Elmonam (2004)(3) pointed out that sex was found to be a significant variable in DVT development. Snow et al., $(2007)^{(26)}$ reported that females were generally at increased risk for DVT. They indicated that it could be related to the pregnancy and using contraceptives. On the other hand, Criner , et al., (2002)(27) identified that the incidence of DVT in hospitalized patients appear to be equal in males and female.

Concerning the body weight, it was found that forty four percent of the studied patients in $\mathrm{G} 1$ and $66 \%$ in $\mathrm{G} 2$ in the present study were overweight and obese. Haines and Stuart $(2003)^{(28)}$ recorded that obese 
patients were found to be high risk for DVT development, due to impaired fibrinolytic system in the obese patients that related to impaired hyper-coagulable state. In contrast, Abd Elmonam (2004) $)^{(3)}$ and Anderson et al., (2003)(29) found that obesity was not a statistical significant factor in the development of DVT. Furthermore, the immobility level is considered risk factor, it was observed that most of the studied patients in the current study were immobile. Geerts et al., (2003)(9) emphasized that immobility is a major risk factor that also affects most of the studied critically ill patients. DVT development was higher in critically ill patients because of bed rest is frequently ordered for monitoring equipment, intravenous lines, drainage tubes, catheters, and other necessary medical equipment.

Regarding the hydration status, it was observed that patients with negative balance were in the moderate and high risk grade of DVT in both groups of the current study. It was documented that the critical care nurses should check skin turgor and the mucous membrane daily, and those who are found to be in need for more fluid should be reported to the physician for proper hydration. Gamal Eldeen (1999)(4), indicated that the critical care nurse should advice the patients to receive at least two liters of fluids per day to prevent increase viscosity of the blood if not contraindicated. As for the connection to the mechanical ventilator, results of the current study revealed that Fifty percent of the studied patients in $\mathrm{G} 1$ and $33 \%$ in $\mathrm{G} 2$ were connected with mechanical ventilator. Gorski et al., (2007)(30) reported that occurrence of DVT is common among critically ill patients requiring prolonged mechanical ventilation more than 7 days in the critical care unit, despite the use of prophylaxis measures. Therefore, they documented that the critical care nurses should monitor the air way, breathing pattern, nutritional status, and psychological 
status for the patients who were connected to the mechanical ventilator. Moreover, the critical care nurses should change the patient's position, perform range of motion exercises for the lower limbs, and monitor of the hydration status to prevent dehydration

Cook and co workers (2001)(1) pointed out that critically ill patients with high risk of DVT and PE and its potential morbidity and mortality, need accurate diagnosis and effective prevention. Therefore, critical care nurses need to understand approaches used for diagnosis, and to understand national interest in DVT research program. The present study shows that preventive measures of DVT done by the critical care nurses for the control group using nonpharmacological and mechanical methods were not adequately performed. It was observed that all the studied patients did not wear the elastic stocking. While small proportion of the studied patients performed leg exercises, and changed their position, did deep breathing exercises and coughing exercises, and transfer on the chair. This inadequacy of DVT preventive measures may be related to the lack of supplies and equipment, lack of in-services training programme about DVT preventive measures, lack of supervision and evaluation. This finding in line with Abd Elmonam (2004)(3) who reported that prevention of DVT using of nonpharmacological methods were not adequately used for orthopedic studied patients.

A previous research done by the Martinelli et al., (2004)(31) strongly recommended the use of mechanical methods of DVT prophylaxis for critically ill patients at increased risk for bleeding. Furthermore, Leizorovice et al (2004) ${ }^{(321}$ documented that mechanical approach can be used in critically ill patients whom pharmacological agents are either contraindication or in whom the likelihood of catastrophic bleeding poses an 
unacceptable risk. Mechanical approach the leg veins. Morris and Woodcock may act in a synergistic manner and as a $(2005)^{(33)}$ pointed out that these measures result provides additional protective benefit are simple to use and did not increase the when combined with mainstay risk of bleeding, making them ideal for most pharmacological prophylaxis. This benefit, hospitalized patients. Moreover, they however, has yet to be demonstrated reported that foot and ankle exercises, empirically in intensive care patients. On planter and dorsiflexion are important to the other hands, Geerts et al., $(2006)^{(9)}$ help improve venous return. While Geerts indicated that the prevention of DVT et al., (2004)(34) stated that the use of this includes anticoagulant medications and exercises is safe for all patients except mechanical methods such as compression those with bone injures. Early ambulation is stocking and intermittent pneumatic another useful technique, it was compression. Moreover, they recommended for decreasing venous recommended that the ideal prophylactic thromboembolism. In addition Khan and agents should be effective, easy to Ginsberg (2004)(35) reported that the role administer and monitor, cost effective, of elastic stocking was based on the perfectly matched to the patients, and free presence of symptoms. On the other hand, of adverse reactions and complications. Kucher and Coldhaber (2005) ${ }^{(36)}$ reported

The critical care nurses should use the that anti-embolic stocking is widely mechanical measures for DVT prevention advocated in the prevention of DVT, but it that include leg exercises, elastic stoking, may do more harm, it may cause heal and deep breathing and coughing exercises pressure ulceration if not used correctly. and sitting on the chair, each improve Dean et al., (1999)(37) recommended that venous return and reduce venous stasis in the critical care nurses should ensure that 
small designed and well fitting stocking is applied and fitted according to calf size and leg length. If stocking is misused it leads to an inverse gradient and decrease venous emptying.

\section{DVT manifestations:}

The signs and symptoms of DVT may include pain, swelling, erythema, and warmth in the affected extremities. Many clinicians still check homen's sign, the presence of calf pain with dorsiflexion of the foot. However, this is no longer considered available indicator of DVT. About half of the patients will have no symptoms, and the first indication may be signs or symptoms associated with PE or even sudden death. That is why preventive intervention and treatment in patients at risk are so imperative $^{(38)}$. Findings of the current study revealed that most of the studied patients experienced low percent of DVT manifestations with no statistical significant difference between the both groups related to rare signs \& symptoms. Moreover,
Qaseem et al., (2007)(39) found that pain \& swelling resolve more quickly and there is no risk for PE. On the other hand, Kahn $(1998)^{(40)}$ emphasized that combination of data about risk factor with signs \& symptoms have better predictive accuracy for the diagnosis of DVT.

\section{DVT risk grades:}

Anderson et al., (2003)(29) have categorized risk of thrombosis into low, moderate, and high risk categories. It was documented that the preventive measures taken by medical and critical care nurse staff will depend on the level of risk for DVT and potential bleeding complications in critically ill patients. The present study revealed that nearly half of the studied patients were in moderate $\&$ high risk grade for DVT in the both groups. This finding could be related to the relative increased age, immobility, alteration of the hydration status, and increase severity of illness of studied patients. A simplified approach to estimate an individual patient's risk, based 
on the presence of predisposing risk important role in DVT prevention. She must factors, might provide a suitable way to cooperate with other health professionals to ascertain a patient's risk. Such a system develop system and quality improvement would allocate patients with a reasonable measure of certainty to low, moderate, or high risk groups so that prophylaxis could be tailored to the element of risk that the critically ill patient is facing ${ }^{(15)}$.

DVT is generally a disorder of critically ill patients, with PE being one of the top preventable killers in these patients. A variety of measures are available to reduce the risk of DVT, these measures include careful risk assessment of the patients and the use of thrombo-prophylactic measures in patients at risk of an event. The introduction of a validated simple bed side tool to estimate the risk of DVT in patients could refine the decision-making process. In view of the thromboembolism event, there is a need for extended prophylaxis in the critical care unit setting to further reduce the incidence of $\mathrm{DVT}^{(36)}$.

The critical care nurses play an processes which are effective in terms of providing quality, and cost effective management for DVT prevention to critically ill patients. She must use keen judgment to detect patients at risk for DVT and to select appropriate interventions to defend against the onset of this problem.

\section{CONCLUSION}

\section{Based on the findings of the current} study, it can be concluded that:

Findings of the current study revealed low incidence of DVT in the global sample, It was observed that the incidence of DVT in the control group was found to be two patients, while none of the interventional group experienced DVT.

Furthermore, it can be concluded that DVT preventive measures done by the nurses for the control group were not adequate. No body was found in the control group wear the elastic stocking, and the mean percent of the studied patients that 
changed their position in G1 was found to be $57.03 \pm 17.4$. While the mean percent of the studied patients that performed deep breathing and cough exercises in $\mathrm{G} 1$ was $2.22 \pm 10.27$. In addition, the mean percent of the patients that performed range of motion for the lower limbs was found to be $10.00 \pm 30.51$, and the mean percent of the studied patients that were Transferred the patient on the chair were found to be $3 \pm 10.0$.

Concerning the DVT manifestations, it was observed that $43 \%$ of the studied patients in the control group experienced DVT manifestations, while in the interventional group was found to be $28 \%$. Furthermore, it was found that most of the studied patients were in the moderate and high risk for DVT $(14<21)$, they constituted about $47 \%$ of the studied patients in G1, and $53 \%$ in $\mathrm{G} 2$, with no statistical significant difference between of them.

\section{RECOMMENDATIONS}

From the findings of the present study the following recommendations are suggested:

- Procession of training programmes for critical care nurses.

- Training program should be established to update critical care nurses' knowledge and skills about DVT preventive measures.

- $\quad$ The CC nurses should be provided with posters of DVT nursing guidelines and handout of the procedures of DVT preventive measures.

- $\quad$ Providing the CC nurses with the DVT preventive devices like elastic stocking, talcum powder, and measuring tape to perform the preventive measures.

- Focused attention to documentation should be done for all procedures for DVT prevention, because of documentation serves to promote the continuity of care given by nurses and other health-care providers.

- Further research is recommended on regular scale in multi certain Egyptian 
hospitals. Repeat this research on a

large sample size and in multi centers

for generalization.

\section{REFERENCES}

1. Cook D, Mullin M, Hodder R, Stewort T. Prevention and Diagnosis of DVT in Critically 111 Patients: a Canadian survey. Crit Care. 2001; 5 (6): 336-42.

2. Attia J, R ay J, Cook D, Doketis J, Giensberg S, Geert W. Prophylaxis of venous thromboembolism in the critically ill . Arch Intern Med. 2001; 161:1268- 79.

3. Abd Elmanam F. Construction of Assessment Scale for patients at high risk for DVT among Orthopedic Patients. Master thesis, Faculty of Nursing, Alexandria University. 2004.

4. Gamal Eldeen G. Implementation of new Regimen as aprophylactaxis against Deep Venous Thrombosis in post operative Patients. Master thesis, Faculty of Nursing, Assuit University, 1999.

5. Joynt G, Kew J, Gomersall C, Leung V, Liu $E$. Deep venous thrombosis caused by femoral venous catheter in critically ill adult patients. Chest. 2000; 117:178 -83 .

6. Mohammed A. Incidence of deep venous thrombosis among surgical patients. Master Thesis, Assuit University Hospital, Faculty of Medicine, 1996.

7. Cook D, Crowther M, Meade M. Deep venous thrombosis in medical-surgical critically ill patients: Prevalence, incidence, and risk factors. Critical Care. 2005; 33: 1565-71.

8. Major $\mathrm{K}$, Wilson M, Nishi $\mathrm{G}$. The incidence of thromboembolism in the surgical intensive care unit. American Surgical. 2003; 69: 857-61.

9. Geerts W, Cook D, Selby R, Etchells E. Venous thromboembolism and its prevention in Critical Care. J Crit Care. 2006; 17: 95-104.

10. Williams M, Aravindan N, Wallace M, Reidal B, Shaw A. Venous thromboembolism in the intensive care unit. Critical Care Clinic. 2004; 19: 185207.

11. Lacherade J, Cook D, Heland D, Church C, Brochard L. Prevention of venous thromboembolism in critically ill patients: a Franco-Canadian crosssectional study. J Critical Care. 2003; 18: 228- 37.

12. Limpus A, Chaboyer W, The use of graduated compression stocking in Australian intensive care units: a national audit. Australian Crit Care. 2003; 16:53-8.

13. Albers G, Amarinco P, Easton J, Sacco $R$, Teal p. Antithrombotic and thrombolytic therapy for ischemic stroke: the Seventh ACCP Conference on Antithrombotic and thrombolytic Therapy. Chest. 2004; 126: Suppl: 4835-5125

14. Thompson J, Mc farland G, H Jane, Tucher. Clinical Nursing. $4^{\text {th }}$ ed. Mosby; 1997: 90 - 4- 60.

15. kozier B, Glenora E, Blais K. Fundamentals of Nursing: London: Addison Wesley Longman; 1998: 561 665.

16. Autar R. Nursing assessment of Clients at risk of DVT: the Autar scale. Journal of Advanced Nursing. 1996 (23): 76370.

17. Potter P, Perry A. Fundamental of Nursing. Philadelphia: Mosby, Inc; 2005: $1452-1478$.

18. Dean R, Brewster D. Current Diagnosis and Treatment in Vascular Surgery. Mexico: Appleton \& Lange Asimon \& Shuster Company; 1998: 375 - 385. 
19. Joffe $H$, Kucher N, Tapson V, Goldhaber S, DVT Steering Committee. Circulation. 2004; 110:1605 - 1611.

20. Rhoades $R$, Planger R. Human Physiology $3^{\text {rd }}$ ed. Atlanta: Saunders College publishing; 1999: 535 - 540 .

21. Amaragiri $S$, Lees $T$. Elastic compression stocking for prevention of DVT. Cochrane Database System Rev. 2003; 3: 1484.

22. Fahey V. Vascular Nursing. $2^{\text {nded. }}$ Chicago: W.B Sanders Company; 1994: 405-425.

23. Eccles M, Mason J. How to develop cost-conscious guidelines. Health Technology Assessment. 2001; 5(16).

24. Wendy M, Kehl G, pruett A. DVT in Hospitalized Patients: A Review of Evidence- based Guidelines for Prevention. Dimensions of Critical Care Nursing. 2006; 25(2): 53-95.

25. Ebell M. Evaluation of the patient with Suspected DVT Journal of Family Practice. 2001; Feb: 1-10.

26. Snow V, Qaseem A, Barry P, Hornbake R. Venous Thromboembolism: A Clinical Practice Guideline from the American College of physicians and the American Academy of Family Physicions. Annals of Family Medicine. 2007; 5:74-80.

27. Criner G, Gilbert E, Alongo D. Critical Care Study Guide. Philadelphia: Springer; 2002: $514-515$.

28. Haines A, Stuart T. venous thromboembolism: pathophysiology and clinical presentation. American Journal of Health-System Pharmacology. 2003; 60 (22): 53

29. Anderson F, Spencer F, spencer F. Risk Factors for venous thromboembolism. Circulation. 2003; 107: 1-16.

30. Gorski F, Lisa A, Carinne F. Venous Thromboembolism: A Common and preventable condition: Implication for the Home Care Nurse. Lippincott: Williams, Inc; February 2007; 25(2): 94-100.

31. Martinelli I, Ballagliolit M, Bucciarellip D, passamonti S, Mannucci M. Risk factors and recurrence rate of primary DVT of the lower extremities. Circulation. 2004; 110: $566-570$.

32. Leizorovicz A, Cohn A, Torbie A, Olsson C, Goldhaber S. The prevention of venous thromboembolism in a critical ill medical patients. Circulation. 2004; 110: 874-9.

33. Morris R, Woodcock J. Evidence-based compression: prevention of stasis and DVT. Ann Surg. 2005; 239:162-71.

34. Geerts W, Heit J, Clagett G. Prevention of venous thromboembolism. Chest 2004; 119: $1325-755$.

35. Kahn S, Ginsberg J. Relationship between deep venous thrombosis and the post thrombotic Syndrome, Arch Intern Med. 2004; 164: 17 - 26.

36. Kucher K, coldhaber S. management of massive pulmonary Embolism. Circulation 2005; 112 (2): 28 - 32.

37. Dean R, James S, Brewster D, Current Diagnosis \& Treatment in vascular Surgery. Mexico: A Simon \& Schuster Company; 1999: 375 -388.

38. Rick B, Daniels R. Nursing Fundamentals Caring \& Clinical Decision Making. Chicago: Thomson; 2004: 312-316.

39. Qaseem A, Snow V, Barry P, Current diagnosis of Venous Thromboembolism in Primary care: a clinical practices guidelines from American Society of Family Physicians and American College of physicians. Anne family Med. 2007; 5(1): 57-62.

40. Kahn S. The clinical diagnosis of DVT. Archives of International Medicine. 1999; 158 (23): 2315-22. 